\title{
Obstrucción recurrente de las vías aéreas en el caballo
}

\author{
Recurrent airway obstruction in horses \\ G Morán ${ }^{1 *}$, O Araya ${ }^{2}$, H Folch ${ }^{1}$ \\ 1 *Instituto de Inmunología, Facultad de Medicina, Universidad Austral de Chile, Becario CONICYT. \\ ${ }^{2}$ Instituto de Ciencias Clínicas Veterinarias, Facultad de Ciencias Veterinarias, Universidad Austral de Chile, \\ Valdivia, Chile.
}

\begin{abstract}
SUMMARY
Recurrent airway obstruction (RAO) is an inflammatory process caused by hypersensitivity due to inhalation of alergen agents, the process is characterized by inflammation of airways, mucus hypersecretion and obstruction. The onset of the disease is triggered by the surrounding where horses are stabled; often abundant organic dust of the hay, straw of bed, dust of the atmosphere, microorganisms contained in airway of the animals and the material of construction of the stable are important predisponent causes of RAO. The symtoms are due to airways inflammation caused by an type I hipersensitivity reaction in first moment, with the consecuent release of histamine and other pro-imflamatory agents, followed by a hipersensitivity reaction type III based on immune complex formation in situ with complement activation, and production of chemioatractants for neutrophils. This imflamatory process induces in other resident cells the activation of many genes using the NF-kB as common trancripcional factor. The diagnosis method for this alergic process is the broncheoalveolar lavage (BAL) followed by cytologic examination. In the case of RAO positive horses, the citology of BAL is characterized by a significant increase of neutrophils and in smaller percentage of eosinophils and mast cells. Administration of glucocorticoids sytemically or by inhalation, reduces the inflammation and obstruction of airways. The bronchodilators drugs also can be used to alleviate respiratory distress. The present work reviews the associated factors involved, the predisponent, the inmmunologic and molecular mechanisms associate to the disease, as well as diagnosis and treatment.
\end{abstract}

Palabras clave: ORVA, vías aéreas, inflamación, caballos.

Key words: RAO, airways, inflammation, horses, review.

\section{INTRODUCCION}

La Obstrucción Recurrente de las Vías Aéreas (ORVA), conocida en ingles como RAO (Recurrent Airways Obstruction), es consecuencia de un proceso inflamatorio originado por una hipersensibilidad debida a la inhalación de agentes alergenos. Esta condición, debido a los mecanismos inmunológicos que intervienen en la patogénesis tiene alguna similitud con el asma humana. Esta patología también es conocida como Enfermedad Pulmonar Obstructiva Crónica (EPOC) (Jackson y col 2000). Pero según Robinson (2001), el término EPOC es inapropiado para describir este cuadro, ya que el tipo de respuesta celular y curso de la enfermedad son diferentes en el cuadro equino con respecto al cuadro en humanos, desde donde se originó dicho término. El EPOC humano es una enfermedad progresiva, caracterizada por su irreversibilidad y asociada con pacientes fumadores. El término EPOC fue introducido por Sasse en 1971 para describir procesos obstructivos de las vías aéreas posteriores de los equinos (Robinson 2001). Esta patología

Aceptado: 15.11.2006.

* Casilla 567, Valdivia, Chile. e-mail: gmoran@uach.cl fue reconocida por Aristóteles en el año 333 a.C., quien describió por primera vez la línea del esfuerzo durante la inspiración en equinos con problemas obstructivos (Dixon 1999). Posteriormente, Markham en el año 1656 relacionó el complejo obstructivo con estabulación y alimentación (Holcombe y col 2001).

El ORVA se caracteriza por inflamación de las vías aéreas, acumulación de mucus y obstrucción reversible, debido a la hipersensibilidad bronquial (Jackson y col 2000), lo que hace que el animal presente una gran disnea, caracterizada por doble espiración abdominal y tos seca. Si la patología lleva varios meses se puede apreciar la llamada línea del esfuerzo, la cual se debe a la hipertrofia de los músculos rectoabdominales. En algunos casos sólo es posible observar una disminución en el rendimiento deportivo del caballo (Araya 1999).

La inflamación de las vías aéreas involucra la activación de células inflamatorias, que liberan una serie de mediadores, que a su vez son responsables de los cambios fisiopatológicos de las vías aéreas (Barnes 1996). Muchas de estas células son residentes del pulmón y otras son atraídas a este órgano y activadas in situ; en estas últimas se incluyen: mastocitos, macrófagos, eosinófilos, linfocitos, células dendríticas, basófilos, neutrófilos y plaquetas. También las células residentes se sabe que es- 
tán involucradas en la síntesis y liberación de mediadores de la inflamación, entre ellas se encuentran las células epiteliales, células del músculo liso y fibroblastos (Levine 1995, Saunders y col 1997).

\section{FACTORES PREDISPONENTES}

La presencia de los antígenos que generan este cuadro dependen de las condiciones ambientales en que se desarrolla la vida de los animales, por ejemplo, el aire de las pesebreras en que se mantienen los equinos es muy abundante en material particulado proveniente del heno, paja de cama, polvo del ambiente, microorganismos y material de construcción de la pesebrera. Por tanto, el ORVA se observa generalmente en equinos estabulados en condiciones deficientes (Araya 1999). La contaminación del ambiente con gases, como amoniaco y metano provenientes de desechos orgánicos, ácaros del polvo y B-D- glucanos, los cuales son componentes de paredes celulares de hongos y bacterias, pueden actuar como alergenos específicos para generar una respuesta inmunitaria alérgica pulmonar (Robinson 2001). Todos estos aerocontaminantes son removidos y suspendidos en el aire por los movimientos y comportamiento alimentario del caballo, y su concentración es mayor alrededor de las fosas nasales que en el resto del ambiente del establo (Araya 1999). Se ha visto que caballos mantenidos estabulados tienen una mayor probabilidad de hacer ORVA comparados con aquellos mantenidos a pastoreo. Por otra parte, si el heno y paja cosechado tienen un alto porcentaje de humedad, el riesgo de contaminación por hongos es también alto y, por consiguiente, la exposición de caballos estabulados a estos hongos es esperable por tanto, las condiciones de estabulación referidas especialmente a la ventilación de los establos, juegan un papel preponderante en la presentación de cuadros alérgicos pulmonares (Araya 1999).

Entre los alergenos más importantes como inductores de este cuadro alérgico están las esporas de Aspergillus fumigatus, hongo oportunista causante de varias patologías respiratorias tanto en hombre como en animales (Kurup y col 2001). Las esporas de este hongo se encuentra principalmente en heno y paja almacenados con 20-30\% de humedad (Araya 1999). También se han encontrado bacterias inductoras de hipersensibilidad pulmonar, como Faenia Rectivirgula y Thermoac-tinomices vulgaris, los que crecen en las mismas condiciones que el Aspergillus fumigatus (MacGorum y col 1998). Por otra parte, los ácaros del polvo son potencialmente alergénicos para humanos y caballos (Hockennjos y col 1981, Gerber 1973). Estos ácaros, en que se destacan Tyrophagus putrescentiae, Cheyletus eruditus, Acarus farris, Ryzoglyphus sp, constituyen también un factor de complicación, ya que algunos de ellos se alimentan de esporas de hongos, las que son eliminadas como pellets fecales (Clarke 1987). Según este mismo autor, los ácaros, además de ser alergénicos de por sí, actuarían también debido a la liberación de alergenos en sus fecas debido a la ingestión de estas esporas. Se ha visto que el incremento de los ácaros, en el heno está directamente relacionado con el número de esporas de hongos, ya que dependen de estas como base de su alimentación (Clarke y Madelin 1987). Araya y Zaror (1995) demostraron la presencia de ácaros en un $80 \%$ de muestras de forrajes en 17 criaderos de caballos chilenos de las provincias de Valdivia y Osorno (Chile) y observaron un incremento de estos ácaros concordante con un aumento de esporas de hongos en los forrajes.

Pareciera ser que una infección respiratoria viral previa de los equinos actuaría como un factor predisponente para desencadenar el cuadro de ORVA; lo más probable es que un animal afectado por un cuadro viral presente una respuesta mucho más severa a la inhalación de esporas de hongo, debido principalmente a la grave alteración producida por los virus sobre el sistema mucociliar, facilitando de esta manera la penetración de las esporas en el sistema respiratorio (Araya 1999). Con respecto a la contaminación urbana, en el hombre se ha visto que la polución provoca un aumento de la signología alérgica pulmonar, deterioro de la función pulmonar, incremento de la hipersensibilidad bronquial y cambios inflamatorios; sin embargo, la interacción de polución y cuadro alérgico pulmonar no han sido probados en equinos.

Diversos reportes sugieren que la presentación de ORVA se debe, en parte, a una predisposición genética debido que se ha encontrado una gran prevalencia de esta patología en grupos familiares de equinos (Gerber 1989). Pero aún es poco claro el rol del componente genético en la presentación de este cuadro alérgico. Al respecto, Martí y col (1991) realizaron un estudio en dos haras para comprobar si el factor genético era determinante para desencadenar este cuadro, no llegando a resultados convincentes. Por otro lado, Marsch y col (1993) sugieren que la presentación del cuadro alérgico pulmonar se debe a la interacción de factores genéticos y ambientales. Recientes estudios han identificado genes inductores de inflamación involucrados en los mecanismos de hipersensibilidad en respuesta de antígenos inhalados (Robinson 2001). Por otra parte, Marti y Horwood (2002) sugieren que, al igual que el asma humano, el ORVA esta condicionado por factores genéticos y que deberían identificarse los genes responsables de la presentación de este cuadro.

\section{REGULACION DE LA REACCION ALERGICA EN PULMONES}

La hipersensibilidad broncopulmonar de tipo I es uno de los factores etiopatogénicos principales del ORVA, lo que fue demostrado por Obel y Schmiterlov en 1948, quienes observaron la misma signología respiratoria, característica de la enfermedad, luego de la administración 
de histamina endovenosa en equinos sanos, los que cursaron con una evidente broncoconstricción (Hoffman 1999). Similares resultados fueron reportados por Derksen y col (1985), quienes encontraron problemas broncopulmonares en ponies luego de la exposición experimental al antígeno que supuestamente desencadena la enfermedad. Estas reacciones de hipersensibilidad están mediadas en parte importante por inmunoglobulina de la clase IgE, responsable clásica de la hipersensibilidad inmediata (figura 1), llamada así por su rápida presentación después de la exposición al antígeno. La IgE se une a las células cebadas y basófilos por medio de su Fc a receptores específicos ubicados en la membrana (FceRI) de estas células, que al ser estimuladas por efecto del antígeno específico liberan al medio extracelular sus gránulos intracitoplasmáticos que contienen una serie de mediadores bioactivos que inducen el desarrollo de la inflamación alérgica (Mekori y Metcalfe 1999). Si una reacción de hipersensibilidad es sistémica e intensa, se denomina anafilaxis y pone en serio peligro la vida del individuo (Gould y col 2003). Otro mecanismo que opera en la etiopatogenia de ORVA es la hipersensibilidad tipo III (figura 2), la cual es responsable de la bronquiolitis neutrofílica originada por la formación de complejos antígeno-anticuerpo y la subsecuente activación de la cascada del complemento, que genera C5a y C3a, péptidos quimiotácticos para polimorfos nucleares neutrófilos, causando por esta vía la característica acumulación de neutrófilos en el árbol bronquial, presente siempre en esta enfermedad (Lavoie 2000). Estos neutrófilos liberan radicales libres y enzimas a los tejidos circundantes, los que causan inflamación y destrucción tisular.

La IgE es una inmunoglobulina termolábil con una estructura convencional de cuatro cadenas: dos cadenas livianas, que pueden ser $\kappa \mathrm{o} \lambda$, y dos cadenas pesadas denominadas $\varepsilon$, que poseen cuatro dominios constantes y un dominio variable, lo que les da un peso molecular aproximado de $200 \mathrm{kDa}$. Esta inmunoglo-

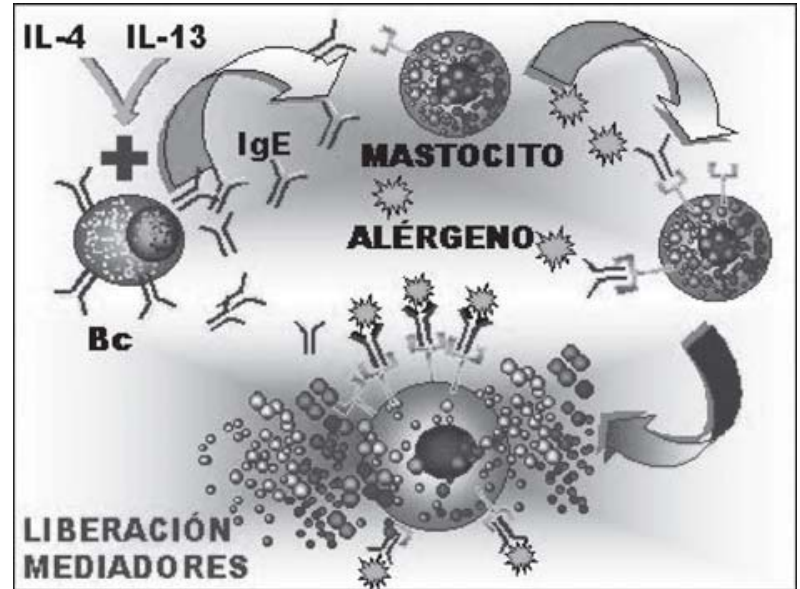

Figura 1. Diagrama de la reacción de hipersensibilidad tipo I. Type I hipersensitivity reaction diagram.

bulina se encuentra en el suero en cantidades muy pequeñas, estando la mayor parte unida a receptores $\mathrm{Fc}$ de células cebadas y basófilos. En el equino recientemente se han identificado los genes que codifican la región constante de la cadena $\varepsilon$ equina, y se ha demostrado que su secuencia aminoacídica tiene un rango de homología de un 45 a $56 \%$ con el ratón y humano respectivamente y sobre un $66 \%$ con la $\operatorname{IgE}$ del perro (Wagner y col 2003). Cuando la IgE se fija a dichas células, tiene una vida media de 11 a 12 días, mucho mayor que la molécula libre circulante. Adicionalmente, algunas subclases de IgG pueden también unirse a las células cebadas y participar en las reacciones de hipersensibilidad tipo I, pero los receptores para estos tipos de inmunoglobulinas son bastante menores en número que los de IgE y pueden considerarse de menor importancia (Galli y Lantz 1999).

Por otra parte, las células T juegan un rol importante en la modulación de la respuesta inmune responsable de la patogénesis del ORVA. Existen dos subpoblaciones

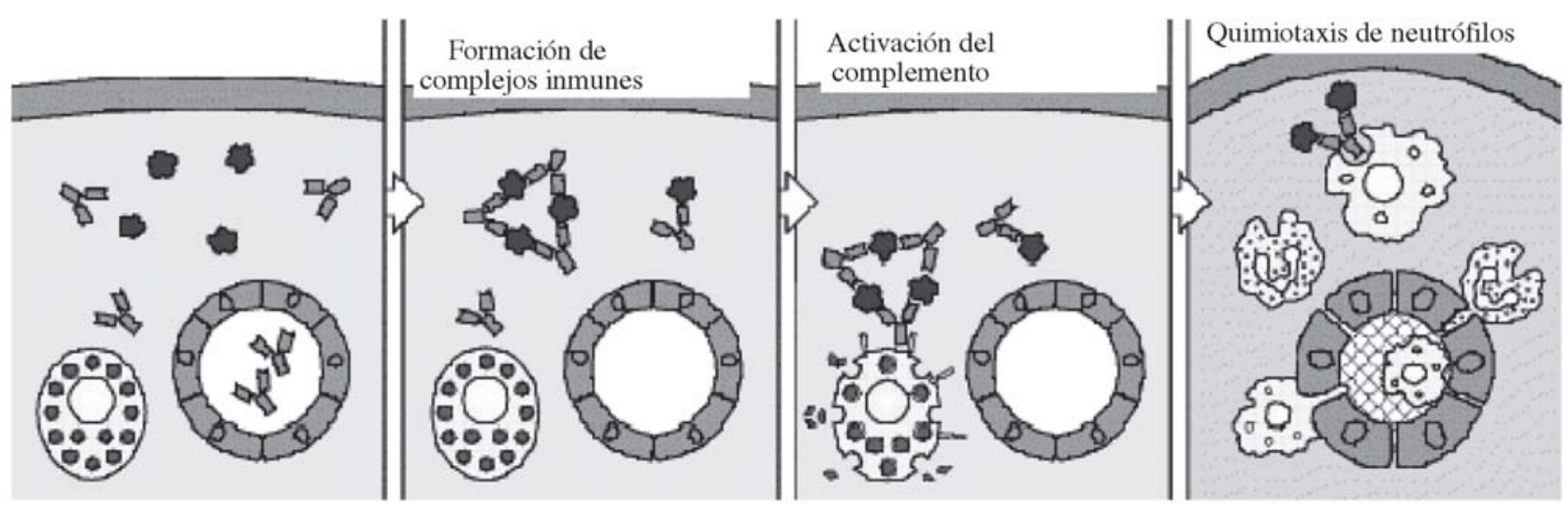

Figura 2. Diagrama de la reacción de hipersensibilidad tipo III. Type III hipersensitivity reaction diagram. 
distintas de célula T auxiliares o "helper" que se distinguen por la combinación de citoquinas que secretan. Estas células se denominan células T auxiliares 1 (Th1) y células T auxiliares 2 (Th2). Las células Th1 producen primordialmente IL- 2 e INF- $\gamma$. Estas células son estimuladas por el IL-12, que a su vez estimula la síntesis de INF- $\gamma$ y otras citoquinas. Uno de los roles de los linfocitos Th1 es actuar como células auxiliares para la respuesta inmune mediadas por células, como las reacciones de hipersensibilidad retardada en las que la activación de macrófagos juega un rol esencial. Por otro lado, las células Th2 secretan IL-4, IL-5, IL-10 e IL-13. Esta mezcla de citoquina estimula la proliferación de células B y la síntesis de inmunoglobulinas y en líneas generales no tiene efecto en la hipersensibilidad retardada u otras reacciones mediadas por células. La respuesta Th2 está vinculada a la inmunidad humoral y, por tanto, a reacciones de hipersensibilidad inmediata o tipo I producidas por alergenos. El rol de la células helper en la patogénesis de cuadros alérgicos pulmonares se demostró tratando ratas con anticuerpos monoclonales anti-CD4 durante la exposición al antígeno; estos animales, a los que por este medio se les destruyeron las células helper Th1 y Th2, no produjeron IL-4 ni IgE y no desarrollaron la enfermedad alérgica pulmonar. A su vez, se observó que una disminución de células T CD8+ obtenido experimentalmente por este mismo método antes de la exposición del antígeno, solo atenuaba la hipersensibilidad pulmonar, la atracción de los eosinófilos al pulmón y bajaba la producción de IL-5; sin embargo, la producción de IgE no se vio afectada en este último caso. Estos resultados demuestran una clara asociación entre la actividad de las células T CD4+, del tipo Th2 e IL-4 en la presentación de enfermedades alérgicas (Lavoie 2001).

Para la síntesis de la IgE, se requiere el proceso de "switching" en donde una célula B en reposo es estimulada y cambia de producción de $\operatorname{IgM}$ a $\operatorname{IgE}$ pasando por las subclases de IgG (Gould y col 2003). Este proceso génico comienza cuando el IL-4 e IL-13 se unen a su receptor en las células $\mathrm{B}$, e inician una serie de mecanismos de transducción de señales que va a culminar en la activación de factores de la transcripción, específicamente STAT6 y NF- $\kappa \mathrm{B}$, los cuales activan una serie de genes involucrados en el proceso de switching (Honjo y col 2002). Además de la activación de estos factores de la transcripción, se necesita la presencia de una enzima que solo se activa en los linfocitos B activados, la citidina desaminasa-inducida (CDI) (Kinoshita y col 2001). Otras de las moléculas importantes en este proceso génico es el CD23, que es un receptor de IgE de baja afinidad. La expresión de este receptor en linfocitos y macrófagos esta regulado por el IL-4 e IL-13, lo que explica que se encuentre incrementado en pacientes atópicos (Gould y col 2003). Muchos estudios sugieren que fragmentos solubles de este receptor serían responsables de estimular la síntesis de IgE. Este receptor sufriría un clivaje mediado por metaloproteasas o productos de digestión de algunos alergenos que tienen funciones enzimáticas como el Dermatophagoides pteronyssinus (Derp p I proteasa), formando pequeños fragmentos de CD23 que estimularían la síntesis de IgE y proliferación de las células B (Gould y col 2003).

Las citoquinas son causantes de muchos procesos proinflamatorios, sirven como un mecanismo de comunicación célula-célula, actúan como factores de crecimiento y tienen un rol en la quimiotaxis, la que contribuye al proceso inflamatorio. Además, como ya hemos visto, modulan la respuesta inmune, inducen la secreción de otras citoquinas y causan en determinadas circunstancias apostosis (Chung y Barnes 1999). Dentro de las citoquinas involucradas en la inflamación alérgica pulmonar, se encuentran principalmente las secretadas por las células del tipo Th2 (IL-4, IL-5 e IL-13); y específicamente para el ORVA equino el IL-8. El IL-4 puede ser producido en las primeras etapas de la respuesta inmune por las células dendríticas dependiendo de un gran número de condicionantes del "medio interno"; pero después durante la respuesta inmune es secretado principalmente por linfocitos del tipo Th2, basófilos y mastocitos. Su síntesis, una vez instaurada la respuesta inmune humoral, también puede estar estimulada por la unión del antígeno a la IgE unida a los receptores Fc de las células cebadas (Barnes y col 1998). Esta citoquina, además de promover el desarrollo de células Th2, inhibe el desarrollo de células Th1, aumenta la actividad citolítica de las células T CD8+ (Barnes y col 1998) e incrementa la expresión de Bcl 2 inhibiendo la apoptosis de células Th2 (Akdis y col 2004). El IL-4 incrementa la atracción y actividad de los eosinófilos e inhibe la apoptosis de estas células mediante un incremento en la expresión de eotaxina (Stienke y Borish 2001). En relación con los cuadros respiratorios, esta citoquina incrementa la expresión de un gen productor de mucina (MUC5AC), produciendo una hipersecresión de las vías aéreas (Chung y Barnes 1999, Gerber y col 2003). A nivel de receptores FceRII (CD23) de mastocitos, esta citoquina aumenta su presencia y afinidad específicas para $\mathrm{IgE}$. Con respecto a esto último Jackson y col (2004) demostraron que esta citoquina estimulaba la expresión de CD23 en células mononucleares periféricas y macrófagos alveolares en equinos. A nivel de los macrófagos, el IL-4 reduce la secreción de IL-1, TNF- $\alpha$, IFN- $\gamma$ e IL-12 y con esto la generación de células Th1. Además, aumenta la expresión de moléculas leucocitarias de adhesión especialmente de las ICAM-1, VCAM-1 y selectinas, que facilitan la adherencia de neutrófilos (Schleimer y col 1992). El IL-13 es sintetizado por células Th2 y su actividad biológica es similar a la IL-4, ya que ambas comparten la afinidad por el receptor de membrana IL-4 $\alpha$ (Wynn 2003). Esta citoquina inhibe la síntesis de IL-1, TNF- $\alpha$ e IL-12, por tanto, permite un mayor desarrollo de células Th2; además, aumenta la expresión de los receptores CD23 de las células 
$\mathrm{B}$, prolonga la supervivencia de los eosinófilos por inducir la expresión de proteínas de superficie especialmente CD69 y tendría algún rol sinérgico en la estimulación de moléculas de adhesión leucocitaria (Mekori y Metcalfe 1999). El IL-5 también tiene un rol importante en la modulación de respuestas alérgicas; esta citoquina es producida por células Th2, células cebadas y eosinófilos, generando un incremento de la producción, maduración, activación y vida media de los eosinófilos (Bandeira-Melo y col 2001; Yamaguchi y col 1998). Además, el IL-5 incrementa la producción eotaxina, la que fue identificada en cerdos con inflamación alérgica pulmonar. En este caso, este quimiotáctico coopera con IL-5 para la movilización de eosinófilos desde la medula ósea hacia la zona pulmonar. Adicionalmente, la eotaxina se ha identificado como precursor de IL-4 (Feder y col 1997; BandeiraMelo y col 2001). Los eosinófilos acumulados en el árbol respiratorio por influencia del IL-5, y estimulados por el factor estimulante de colonias de granulocitosmacrófagos (GM-CSF), promueven la producción de superóxidos y la expresión de antígenos de histocompatibilidad clase II, incrementando el proceso inflamatorio. En el árbol bronquial, el GM-CSF es una citoquina que proviene de células $\mathrm{T}$, macrófagos, eosinófilos, fibroblastos, células endoteliales, células de la musculatura lisa y células epiteliales.

Con estos antecedentes se ha demostrado que el uso de anticuerpos anti IL-5, en seres humanos, reduce notablemente la movilización de eosinofilos a la zona pulmonar y como consecuencia se reduce la respuesta inflamatoria alérgica (Chung y Barnes 1999). El IL-8 también juega un rol importante en la modulación de la enfermedad alérgica pulmonar. Esta citoquina es producida por células inflamatorias como macrófagos, monocitos, linfocitos, eosinófilos y células residentes del pulmón como células epiteliales, células de la musculatura lisa y células endoteliales. El efecto de IL-8 sobre las vías aéreas se debe a su capacidad de atraer y activar neutrófilos estimulando la exositosis de sus gránulos (Barnes y col 1998). Estos efectos explican los hallazgos de Franchini y col (2000), que demostraron un incremento del IL-8 en el LBA en caballos con ORVA y que este incremento presentaba una correlación positiva con el aumento del número de neutrófilos, lo cual se relaciona con los resultados de Art y col (1999), que demostraron un aumento del estrés oxidativo a nivel pulmonar debido a la gran infiltración neutrofílica durante el cuadro de ORVA.

\section{PATOLOGIA MOLECULAR}

Tal como hemos mencionado, el ORVA es una condición inflamatoria de las vías aéreas generada por una hipersensibilidad inducida por agentes inhalados. Esta relación entre inflamación e hipersensibilidad es el resultado de la expresión exagerada de los genes inflamatorios, producidos por la activación de factores de la transcripción que inducen la expresión de estos genes (Bureau y col 2000a). Dentro de los factores de la transcripción descritos en caballos con ORVA, se encuentra el NF- $\kappa \mathrm{B}$ (Bureau y col 2000a). La actividad del $\mathrm{NF}-\kappa \mathrm{B}$ sobre los bronquios está correlacionada por el porcentaje de neutrofilos encontrados en el lavado bronqueoalveolar (LBA) (Bureau y col 2000a; Sandersden y col 2001). La activación de este factor es producido por la producción persistente del TNF- $\alpha$ e IL-1 $\beta$ secretadas por las células inflamatorias. Por esto último, se han desarrollado anticuerpos anti-TNF- $\alpha$ y anti-IL-1 $\beta$ produciendo una supresión de la actividad del NF- $\kappa \mathrm{B}$; asimismo, aumenta la expresión de la proteína $\mathrm{I} \kappa \mathrm{B}$, la cual tiene un efecto inhibitorio de la actividad de este factor de transcripción (Bureau y col 2000a). Esto explicaría, en parte, la inflamación neutrofílica en individuos con ORVA (Bureau y col 2000a, Sandersden y col 2001). En resumen, el NF- $\kappa \mathrm{B}$ juega un rol crucial en la inducción de la transcripción de muchos genes involucrados en esta enfermedad, incluyendo factores quimiotácticos, citoquinas, receptores para citoquinas y moléculas de adhesión celular (Umland y col 2002).

\section{MECANISMOS FISIOPATOLOGICOS DE LA BRONCOCONSTRICCION}

La broncoconstricción de la musculatura lisa bronquial es producida básicamente por la acción que ejerce la histamina sobre las vías aéreas. La acción de la histamina, en este caso, está mediada por tres receptores específicos de membrana de las células musculares lisas bronquiales (Barnes y col 1998, Robinson 2001). Los receptores $\mathrm{H} 1$ y $\mathrm{H} 2$ que fueron descritos por Ash y Schild en 1966 (Schultz y col 1991) y un tercer receptor fue reconocido recientemente $(\mathrm{H} 3)$, cuya función primordial es a nivel del sistema nervioso. En la musculatura lisa bronquial hay dominio de receptores $\mathrm{H} 1$ sobre receptores $\mathrm{H} 2$. La histamina produce broncoespasmo dado por los receptores $\mathrm{H} 1$ bloqueando los receptores $\mathrm{H} 2$ de la musculatura lisa (Barnes y col 1998). Cuando el receptor $\mathrm{H} 1$ se una a la histamina se produce la formación del 1,4,5-triofosfato de inositol (IP3) por la activación de la fosfolipasa $\mathrm{C}$, el cual se une a un receptor del retículo endoplásmico liso (REL), lo que conduce a la liberación de iones de $\mathrm{Ca}++$, que junto al diacilglicerol (DAG) activa la proteincinasa $\mathrm{C}$, produciéndose la contractibilidad de la musculatura lisa. Además, el DAG y el $\mathrm{Ca}^{2+}$ activan la fosfolipasa A2 que estimula la formación de ácido araquidónico (Barnes y col 1998). Los receptores H2 median la broncodilatación, la cual ha sido identificada en diferentes especies, incluyendo gatos, ratas, conejos, ovejas y equinos (Chand y Eyre 1975). La histamina también estimula la secreción de mucus de las vías aéreas (Barnes y col 1998), incrementa la expresión de moléculas de adhesión leucocitaria (Vignola y col 1993), 
influencia la secreción y liberación de citoquinas (Falvs y Merety 1992). La otra causa de broncoconstricción es mediante mediadores colinérgicos, habiéndose visto que la histamina tiene efectos sobre los nervios terminales postganglionares, estimulando la secreción de acetilcolina (Barnes 1992). Esta exagerada liberación de acetilcolina provoca una broncoconstricción en individuos con ORVA (Zhang y col 1999). La liberación de acetilcolina de los nervios parasimpáticos está controlada por los receptores muscarínicos, de los cuales hasta ahora se han reconocido cuatro tipos (M1, M2, M3 y M4). La contracción de la musculatura lisa es mediada por los receptores M3 tanto en humanos como en animales. Cuando la acetilcolina se une a una célula de músculo liso, el receptor M3 de ésta unido a su ligando, al igual que los receptores $\mathrm{H} 1$ activa a una proteína $\mathrm{G}$, que a su vez activa la fosfolipasa $\mathrm{C}$ que catalizara la formación de DAG e IP3, con lo cual se libera de $\mathrm{Ca}++\mathrm{y}$ activa la protincinasa C produciendose la contractibilidad de la musculatura lisa. En 1984 Fryer y Maclagan demostraron que la secreción de acetilcolina es controlada por los receptores M2 de los nervios parasimpáticos postganglionares presentes en la vías aéreas. Estos receptores proporcionan un mecanismo de feedback negativo, lo que cual inhibe la secreción de acetilcolina. Los eosinófilos juegan un rol importante en el bloqueo de los receptores M2 que ejercen por medio de sus proteínas (proteína catiónica eosinofílica y eosinofilia peroxidasa); en contrate los receptores M3 no son afectados por estas cargas proteicas. Por lo tanto, el bloqueo de los recptores M2 incrementa la liberación de acetilcolina y potencia la actividad parasimpática en las vías aéreas (Fryer y Jacoby 1998, Olszewski y col 1999).

\section{SIGNOS CLINICOS}

Los caballos con ORVA se caracterizan por presentar tos, la cual se describe en el $85 \%$ de los casos; descarga nasal, la que a menudo es mucopurulenta debido a infecciones bacterianas secundarias, pero en general la secreción de la mucosa respiratoria se visualiza preferentemente en el tracto respiratorio bajo que en la cavidad nasal (Dixon 1999); disnea expiratoria y reducción de la "performance" (Eder y col 2000). De los signos clínicos del ORVA, el distres respiratorio debido a la broncoconstricción de la musculatura lisa bronquial, producido básicamente por la acción que ejerce la histamina sobre las vías aéreas, es una de las más importantes. En ciertos caballos no se aprecia una signología clínica importante y sólo es posible observar un menor rendimiento de la capacidad atlética del animal. Esta intolerancia al ejercicio es debida a la disfuncionalidad pulmonar durante el cuadro alérgico, y puede producirse tanto en velocidades maximales como submaximales (Art y col 1998). Estos autores sostienen que los equinos que presentan ORVA requieren un $40 \%$ más de consumo de oxígeno, produciendo así un aumento de la concentración del lactato plasmático debido al deterioro de la fosforilación oxidativa, además de una temprana activación de la glicólisis anaeróbica y una baja en la actividad de las enzimas mitocondriales, siendo probablemente esta la principal causa de esta intolerancia.

Actualmente están disponibles diversos métodos para evaluar la funcionalidad pulmonar, tales como presión pleural (Ppl), elasticidad pulmonar (Ep), resistencia pulmonar (Rp) y trabajo respiratorio (R) (Robinson 2001). Los caballos normales usualmente tienen una Ppl de 2-5 $\mathrm{mmHg}$ por cada ciclo respiratorio; en cambio, en individuos con ORVA la Ppl puede llegar a ser mayor que $6 \mathrm{mmHg}$ (Dixon 1999). Estudios realizados por Art y col (1998) demostraron que la Ppl alcanzada en caballos con ORVA fue de $8,32 \mathrm{mmHg}$, y en individuos con el cuadro en remisión la Ppl alcanzó 6,83 $\mathrm{mmHg}$. Por otra parte, Couëtil y col (2000) también demostraron un aumento de la Ppl en caballos con ORVA en comparación con individuos sanos. Además, del aumento de la Ppl, también existe un aumento de la Rp y de R y una disminución del Ep (Robinson 2001). Por otra parte, también se ha demostrado que existe una hipercapnia y una hipoxemia durante el ejercicio en individuos positivos a ORVA (Art y col 1998). Estos mismos autores sugieren que la hipoxemia es debida a la falta de una hiperventilación compensatoria. El organismo, en compensación al pobre intercambio gaseoso, produce una intensa redistribución del flujo sanguíneo especialmente del lóbulo diafragmático en su porción dorso caudal (Harmegnies y col 2002) y estimula la neoformación de vasos capilares pulmonares desde las arterias bronquiales. Sin embargo, estos capilares neoformados son muy frágiles para resistir el incremento de la presión durante el ejercicio, produciendose así hemorragia pulmonar inducida por el ejercicio (Derksen y col 1992; Robinson 2001; Newton y Word 2002).

\section{DIAGNOSTICO}

Dentro de los métodos de diagnóstico más utilizados para identificar caballos con ORVA está el lavado bronqueoalveolar (LBA). Esta técnica fue implementada por Viel en Canadá en 1980; desde entonces se ha hecho cada vez más popular por su simplicidad, bajo costo y utilidad en el diagnóstico diferencial entre enfermedades pulmonares infecciosas y alérgicas (Moore y Cox 1996). Por otra parte, se ha visto que la evaluación citológica vía LBA es más consistente entre caballos normales que la citología de la aspiración transtraqueal (AT) y demostrándose una excelente correlación entre citología al LBA e histopatología pulmonar a diferencia de la AT (Araya 1999). Estudios realizados por Derksen y col (1989) demostraron la pobre correlación que existe entre el conteo relativo de neutrófilos entre AT y LBA, en donde se exhibió una diferencia de un 95\% (0-88\% y 
4-68\% respectivamente), lo que limita su utilidad clínica en los caballos con ORVA. Además, la composición del LBA es uniforme a través del pulmón en caballos con enfermedad difusa, siendo representativa de la severidad de la inflamación pulmonar (Moore y Cox 1996, Araya 1999). Comúnmente el procedimiento se realiza con el caballo sedado de pie y pudiendo ser efectuado a través de un endoscopio fibroóptico largo o de un catéter para LBA. El fluido infundido (150-300ml) consiste en una solución fisiológica estéril a $37^{\circ} \mathrm{C}$, este fluido es instalado y reaspirado (30-50\% del total del fluido) para su posterior evaluación (Robinson 2001). En animales sanos, la mayor población de células consiste en macrófagos alveolares, linfocitos, células cebadas; además, se pueden encontrar pequeñas cantidades de células epiteliales bronquiales ciliadas y no ciliadas, algunos neutrófilos y eosinófilos (McGorum y Dixon 1994). Durante una exacerbación del ORVA la citología se caracteriza por un significante incremento de neutrofilos y en menor grado de eosinófilos y mastocitos (Robinson 2001). Por otra parte, el análisis de los fluidos del LBA ha facilitado la evaluación microbiológica y de constituyentes no celulares como mediadores inflamatorios y citoquinas (Franchini y col 1998).

La evaluación del ORVA mediante endoscopía flexible permite visualizar todo el tracto respiratorio en forma directa y así identificar secreciones mucopurolentas, características mucosas, visualizando zonas hiperémicas y broncoespástica en la vías aéreas (Hare y Viel 1998).

\section{TRATAMIENTO}

Los glucocorticoides (Gcs) son el tratamiento de elección para los problemas pulmonares alérgicos, ya que ellos inactivan al NF- $\mathrm{B} \mathrm{y}$, por tanto, alteran la transcripción de proteínas asociadas con la inflamación, bloquean la producción y liberación de citoquinas, disminuyen la expresión de moléculas de adhesión e influyen en la presencia de células que median la inflamación, estabilizan e inducen la formación de receptores $\beta$-adrenérgicos, recuperando de esta manera la funcionalidad pulmonar (Robinson 2001). Sin embargo, diversos reportes sugieren cierta resistencia de los Gcs en individuos con asma humana (Corrigan y col 2004). Se ha demostrado que esta resistencia para este tipo de fármacos es producida por una gran actividad del NF-кB у AP-1, que son importantes factores de la transcripción involucrados en la expresión de genes inflamatorios; estos tendrían un efecto negativo sobre el receptor de glucocorticoides en la célula, específicamente el receptor RG $\alpha$, por inhibir su afinidad con los Gcs (Pujols y col 2004, Corrigan y col 2004). La secuencia de eventos de la acción de los Gcs comienza cuando estos difunden a través de la membrana celular y se unen a los receptores de glucocorticoides (RGs), los que se encuentran en el citoplasma de las células. Este complejo Gcs-RGcs está asociado a la hsp90 (heat shock protein), la cual es una proteína chaperona que estabiliza la unión del complejo (Umland y col 2000). Posteriormente, el complejo se transloca al núcleo donde reconoce secuencias específicas del DNA, llamadas elementos respuesta a glucocorticoides (ERG). Específicamente los Gcs reconocen secuencias intensificadoras (enhancer), que van a estimular al complejo TATA BOX para iniciar la transcripción de genes involucrados en disminuir los efectos adversos de un cuadro pulmonar alérgico (Umland y col 2000). La administración sistémica de Gcs es efectiva como tratamiento en caballos con ORVA, habiéndose establecido que la dexametasona $(0.1 \mathrm{mg} / \mathrm{kg})$ mejora ostensiblemente la función pulmonar dentro de los 3 días de tratamiento y con un mejoramiento continuado hacia el día 7 (Rush y col 1998a) y, además, reduce significativamente el número de neutrófilos en el LBA (Rush y col 1998b). Sin embargo, la dexametasona suprime la función adrenocortical entre los días 2 y 4 del tratamiento, pero la producción de cortisol endógeno se reanuda 2 a 4 días después de discontinuar la droga no afectándose la prueba de estimulación del ACTH por un periodo de 7 días de tratamiento (Rush y col 1998a). Por otra parte, la prednisona oral es inefectiva en la prevención o tratamiento del ORVA, aunque produce una reducción del número de neutrófilos en el LBA, pero no produce una recuperación de la funcionalidad pulmonar (Jackson y col 2000). En contraste con la prednisona, la prednisolona oral $(2,2 \mathrm{mg} / \mathrm{kg})$ es altamente efectiva en el tratamiento del ORVA (Robinson 2001). Una sola dosis de triamcinolona $(0,09 \mathrm{mg} / \mathrm{kg}, \mathrm{IM})$ alivia considerablemente la funcionalidad pulmonar por 4 semanas, pero produce una evidente supresión adrenal (Lapointe y col 1993). Los Gcs aerosolizados también son efectivos en el tratamiento del ORVA y han sido extensivamente investigados (Robinson 2001). La beclometasona (5 puff, 500 ug) produce una disminución del número de neutrófilos en el LBA, disminuye la proporción de la subpoblación de linfocitos CD4+ y B, recuperándose la funcionalidad pulmonar (Rush y col 1998c). Sin embargo, al igual que la dexametasona produce una supresión adrenocortical, pero sin afectar la estimulación del ACTH. Por otra parte, la recuperación de los efectos clínicos y de la funcionalidad pulmonar no ocurren de inmediato, sino dentro de las primeras 24 horas postadministración de beclometasona (Rush y col 2000). Otro de los Gcs aerolizados es la fluticasona (9 puff, $2000 \mathrm{ug}$ ); con respecto a este fármaco se ha visto que es el Gcs más efectivo, por permanecer más tiempo en el pulmón y el que tiene un menor potencial de producir supresión adrenal (Varner y Busse 1996). El efecto relativo de la transcripción genómica de algunos Gcs fue medidos in vitro mediante cotransfección de líneas celulares (CV-1) con un vector que contenía RG y un plásmido reportero que expresaba cloranfenicol acetiltranferasa (CAT) para visualizar el efecto de la transcripción de los Gcs. 
La fluticasona fue el más potente activador de la transcripción seguido de triamcinalona y de dexametasona, la cual tuvo un efecto menor en comparación con los dos primeros. Asimismo, en otro estudio la fluticasona demostró tener una mayor afinidad de ser captada por los RG a diferencia de la triamcinolona y la dexametasona; esta última tuvo una menor afinidad. Esto explicaría, en parte, la mayor persistencia de la fluticasona en el pulmón una vez administrada (Umland y col 2002).

La combinación terapéutica de broncodilatadores con Gcs es apropiada en aquellos caballos que presenten ORVA moderado a severo. Los Ges alivian la broncoconstricción, pero el efecto no es inmediato, por tanto, los broncodilatadores debieran ser la primera línea terapéutica de emergencia para aliviar la obstrucción severa (Rush y col 2000). Alternativamente, se pueden ocupar broncodilatadores inhalatorios o endovenosos $15 \mathrm{minu}-$ tos antes de usar Gcs inhalatorios, para producir una mejor distribución de estos últimos en las vías aéreas (Robinson 2001). Los agonista $\beta 2$-adrenérgicos son los broncodilatodores más usados en medicina equina; estos relajan la musculatura lisa bronquial a través de la activación de la adenilciclasa y la elevación del AMPc intracelular, el cual produce, en primer lugar, la activación de la proteincinasa A y la fosforilación de la cinasa de la cadena ligera de la miosina, la cual fosforilada es inactiva, ya que pierde afinidad con el $\mathrm{Ca}++\mathrm{y}$, por tanto, un menor acoplamiento actina-miosina. Adicionalmente los Gcs sensibilizan los receptores $\beta 2$-adrenérgicos pulmonares previniendo su desensibilización, probablemente aumentando la transcripción de proteínas receptoras, por lo tanto, incrementan la respuesta de los fármacos $\beta 2$-adrenérgico (Flores y col 1992). Entre los agonistas $\beta 2$-adrenérgicos se encuentra el clenbuterol $(0,8-3,2 \mathrm{ug} / \mathrm{kg})$, el cual, además de ser un broncodilatador, produce un aumento del clearance mucociliar. Las altas dosis de este broncodilatador producen temblores musculares, sudoración, taquicardia y excitación; efectos generalmente de corta duración. El albuterol es otro agonista $\beta 2$-adrenérgico, que al ser administrado en forma oral no ha demostrado una eficacia broncodilatadora. El uso de broncodilatadores inhalatorios ha sido efectivo como tratamiento del ORVA, pero su efecto es relativamente corto. Por ejemplo, el efecto del albuterol y pirbuterol es alrededor de 1 a 2 horas, mientras el salmeterol tiene un efecto un poco más prolongado con unas 8 horas postaplicación (Robinson 2001). Los fármacos anticolinérgicos, como la atropina $(0,02 \mathrm{mg} / \mathrm{kg})$ y el ipatropium (20 puffs, 360 ug) también son usados en el cuadro de ORVA por su acción broncodilatadora (Robinson 2001). Estos bloquean competitivamente la acción de la acetilcolina liberada en las terminaciones postganglionares que llegan a la musculatura lisa bronquial. Su eficacia terapéutica dependerá hasta qué punto el reflejo colinérgico bronconstrictor contribuya al broncoespasmo total presente en el cuadro clínico concreto. Mediante la administración vía inhalatoria (ipatropium) es posible aumentar la concentración localmente, minimizando los efectos secundarios propios del bloqueo muscarínico en otros órganos (Flores y col 1992). Los agonistas $\alpha 2$-adrenérgicos, como la xilazina, detomidina y romifidina producen una dilatación de las vías aéreas en caballos con ORVA debido a que suprimen la liberación de acetilcolina de los nervios parasimpáticos. Esta clase de droga, debiera ser usada como premedicación anestésica en caballos con broncoespasmo (Robinson 2001).

El objetivo fundamental del empleo de fármacos mucolíticos es el de facilitar su expulsión del tracto respiratorio (Robinson 2003). Flores y col (1992) han delimitado los mucolíticos como aquellos fármacos que modifican las características fisicoquímicas de la secreción traqueobronquial de manera que la expectoración sea más eficaz y cómoda. Los mucolíticos más usados en medicina equina son la bromhexina, que deriva de un alcaloide de la nuez del malabar, y el ambroxol; uno de sus metabolitos activos tiene mayor potencia que la bromhexina. La acción que ejercen estas drogas in vitro es de depolimerizar las mucinas, glicoproteínas de las secreciones, con reducción de la viscoelasticidad. Estudios realizados en animales han demostrado que ha dosis alta de estas drogas produciría una acción regeneradora de las células epiteliales ciliadas (Flores y col 1992). Sin embargo, tanto en pacientes humanos con asma y caballos con ORVA no existe una evidencia científica clara sobre los efectos clínicos de estos fármacos (Lekeux y Duvivier 2001).

El uso de estabilizadores de células cebadas, como el cromoglicato de sodio, puede ser de gran utilidad para prevenir episodios de broncoconstricción, al inhibir la liberación de los mediadores en la musculatura lisa bronquial (Hare y col 1994). Este fármaco no posee propiedades broncodilatadoras por sí mismo, ni antagoniza los receptores histamínicos u otros mediadores, pero profilácticamente impide el broncoespasmo; para ello es necesario que el fármaco actúe antes que los alergenos. Esta acción protectora, sin embargo, no es común a todos los tejidos; estudios demostraron una buena actividad farmacológica en el tejido pulmonar, pero no en la piel (Thompson y McPherson 1981). La capacidad del cromoglicato de sodio para impedir la liberación de los mediadores bioactivos del mastocito pulmonar parece deberse a la interferencia que tiene este con el $\mathrm{Ca}++$. Por una parte, este fármaco facilita la fosforilación de proteínas de membranas que originaría una inhibición de la entrada de $\mathrm{Ca}++$ a la célula; por otra parte, el cromoglicato podría formar complejos con los iones calcio, bloqueando los canales $\mathrm{Ca}++$ (Flores y col 1992). Varios estudios han demostrado la efectividad del cromoglicato de sodio para prevenir episodios de ORVA en los caballos; por ejemplo, una nebulizacion de $80 \mathrm{mg}$ por 1 a 4 días previene la presentación de ORVA por unas tres semanas aproximadamente (Soma y col 1987). Otros autores 
mencionan que este fármaco favorece la prevención de la hemorragia pulmonar inducida por el ejercicio en caballos de carrera por reducir el reflejo vagal broncocostrictivo (Hillidge y col 1987). No obstante la dosis recomendada es de $80 \mathrm{mg}$ cada 24 horas por 4 días (Robinson 2003).

Los tratamientos de desensibilización, con inoculaciones con el antígeno causal, tienen como fin estimular la producción de anticuerpos de IgG bloqueadores que compitan con la IgE por el antígeno y, por tanto, impidiendo que llegue este a las células cebadas; también es probable que estas inmunizaciones estimulen la liberación de IFN- $\gamma$ e IL-12 por parte de las células Th1 y macrófagos respectivamente bloqueando la síntesis de IgE. Por otra parte, se ha reportado que estos tratamientos de desensibilización estimulen la expresión y síntesis de IL-10, el cual generaría células T reguladoras inhibiendo la respuesta tipo Th2 (Akdis y col 2004). Estos mismos autores, sugieren que esta citoquina no sólo produce cierta tolerancia de las células $\mathrm{T}$, sino que también regula la síntesis de anticuerpos reargínicos. Sin embargo, no se ha descrito este procedimiento en los caballos que sufren ORVA.

Probablemente en el futuro y debido a los avances tecnológicos en enfermedades alérgicas pulmonares en humanos, la terapia génica pueda ser aplicada como manejo terapéutico en individuos con ORVA. Uno de los blancos de la terapia génica sería el NF- $\kappa B$, ya que este factor de la transcripción juega un rol importante en la transcripción de los genes que codifican una serie de mediadores inflamatorios (Bureau y col 2000b). La inhibición del NF- $\kappa \mathrm{B}$ se debiera conseguir mediante la transfección de genes que cumplan funciones de inhibidores intracelulares o desarrollar genes que codifiquen oligonucleótidos que compitan con los sitios de unión del NF-אB en el DNA (Griesenbach y col 2000).

Es conveniente resaltar que ningún tratamiento medicamentoso será efectivo si no se mejoran las condiciones de estabulación de los animales y se efectúa un adecuado diagnóstico de la contaminación del heno y paja por hongos, manteniendo una buena circulación de aire en las pesebreras. El tratamiento medicamentoso sólo será de utilidad en el sentido de recuperar el caballo de la signología clínica presente, pero no tiene valor en esta patología efectuar un tratamiento sin la complementación de las medidas de manejo ambiental (Araya 1999).

\section{RESUMEN}

La Obstrucción Recurrente de las Vías Aéreas (ORVA) es un proceso inflamatorio como respuesta a una hipersensibilidad debida a la inhalación de agentes alergenos, la cual se caracteriza por una inflamación de la vías aéreas, acumulación de mucus y una obstrucción reversible debido a la hipersensibilidad bronquial. El aire de las pesebreras en que se mantienen los equinos es muy abundante en material particulado proveniente del heno, paja de cama, polvo del ambiente, microorganismos contenidos en el ambiente y en las vías respiratorias de los animales y material de construcción de la pesebrera; por lo tanto, el ORVA se observa en equinos estabulados y su presentación está asociada con una estabulación deficiente. Esta relación entre inflamación e hipersensibilidad es el resultado de la expresión exagerada de genes que codifican para medidores inflamatorios. Esta expresión génica depende de la activación de factores de transcripción relacionados con el proceso. El NF-kB juega un rol crucial en la inducción de la transcripción de muchos genes involucrados en esta enfermedad, incluyendo quimiotácticos, citoquinas, receptores citoquínicos, moléculas de adhesión celular y células leucocitaria. El diagnóstico de elección de este cuadro alérgico es el lavado bronqueoalveolar (LBA), ya que durante una exacerbación del ORVA la citología es caracterizada por un significativo incremento de neutrófilos y en menor grado eosinófilos y mastocitos. La administración de glucocorticoides sistémicos o por inhalación reduce la inflamación y la obstrucción de las vías aéreas. Las drogas broncodilatadoras también deberían ser usadas para disminuir la dificultad respiratoria. La presente revisión pretende dar una visión actualizada sobre los factores que inciden en la presentación de esta patología, mecanismos inmunológicos y moleculares envueltos, como así también diagnóstico y tratamiento.

\section{REFERENCIAS}

Akdis M, C Schmidt-Weber, M Jutel, CA Akdis, K Blaser. 2004. Mechanism of allergen immunotherapy. Clin Exp All Rev 4, 56-60. Araya O. 1999. Enfermedades respiratorias crónicas en caballos y su relación con estabulación deficiente en Chile. Curso de afecciones respiratorias en caballos, Hospital Veterinario. Universidad Austral de Chile, Valdivia, Chile.

Araya O, L Zaror. 1995. Determinación de esporas de hongos y ácaros de vida libre en heno y paja en criaderos de caballos chilenos. Arch Med Vet 2, 41-45.

Art T, D Duvivier, D Votion, N Anciaux, S Vandenput, W Bayly, P Lekeux. 1998. Does an acute COPD crisis modify the cardiorespiratory and ventilatory adjustment to exercise in horses? J Appl Physiol 84, 845-852.

Bandeira-Melo C, A Herbst, P Welle. 2001. Eotaxin: Contributing to the diversity of eosinophil recruitment and activation. Am J Resp Cell Mol Biol 24, 653-657.

Barnes PJ, K Fan Chung, C Page. 1998. Inflammatory mediators of asthma: An Update. Pharmacological Reviews 50, 515-596.

Barnes PJ. 1992. Modulation of neurotransmission in airways. Physiol Rev 72, 699-729.

Barnes PJ. 1996. Pathophysiology of asthma. Br J Clin Pharmacol 42, 3-10.

Bureau F, G Bonizzi, N Kirschvink, S Delhalle, D Desmecht, MP Merville, V Bours, P Lekeux. 2000a. Correlation between nuclear factor- $\mathrm{\kappa B}$ activity in bronchial brushing samples and lung dysfunction in an animal model of asthma. AM J Resp Crit Care Med 161, 1314-1321

Bureau F. S Delhalle, G Bonizzi, L Fievez, S Dogne, N Kirschvink, A Vanderplasschen, MP Merville, V Bours, P Lekeux. 2000b. Mechanisms of persistent NF- $\mathrm{KB}$ activity in the bronchi of an animal model of asthma. J Immunol 165, 5822-5830.

Campbell E, S Kunkel, R Strieter, N Luckas. 2000. Differential role of Il-18 in allergic airway disease: Induction of eotaxin by resident cell populations exacerbates eosinophil accumulation. J Immunol 164, 1096-1102.

Chand N, P Eyre. 1975. Classification and biological distribution of histamine receptor subtypes. Agents Actions 5, 277-295.

Chung K, P Barnes. 1999. Cytokines in asthma. Thorax 54, 825-857.

Clarke AG. 1987. Stable environment in relation to the control of respiratory diseases. Horses Management. Ed J Hickman, Pp 125-174. 
Clarke AG, T Madelin. 1987. Technique for assessing respiratory health hazards from hay and other source materials. Equine Vet $J$ 19, 442-447.

Corrigan CJ, CM Hawrylowicz, P Lavender, TH Lee. 2004. Glucocorticoid-resistant asthma. Clin Exp All Rev 4, 200-204.

Couëtil LL, FS Rosenthal, CM Simpson. 2000. Forced expiration: a test for airflow obstruction in horses. J Appl Physiol 88, 1870-1879.

Derksen FJ, NE Robinson, PJ Armstrong, RF Slocombe. 1985. Airway reactivity in ponies with recurrent airway obstruction ("heaves"). J appl Physiol 58, 598-604.

Derksen FJ, CM Brown, I Sonia, BJ Darien, NE Robinson. 1989. Comparison of transtracheal aspirate and bronchoalveolar lavage cytology in 50 horses with chronic lung disease. Equine Vet $J$ 21, 598-604.

Derksen FJ, R Slocombe, P Gray. 1992. Exercise induced pulmonary hemorrage in horses with experimentally induced allergic lung disease. Am J Vet Res 53, 15-21.

Dixon PM. 1999. Equine Chonic Obstructive Pulmonary Disease (COPD). Curso de afecciones respiratoria en caballos, Hospital Veterinario. Universidad Austral de Chile, Valdivia, Chile.

Eder C, I Curik, G Brem, R Crameri, I Bodo, F Habe, S Lazary, J Solkner, E Marti. 2001. Influence of environmental and genetics factors on allergen-specific immunoglobulin-E levels in sera from Lipizzan horses. Equine Vet J 7, 714-20.

Falvs A, K Merety. 1992. Histamine: An early messenger in inflamatory and immune responses. Immunol Today 13, 154-156.

Feder L, D Stelts, D Chapman, D Manfra, Y Crawley, H Jones, M Minnicozzi, X Fernandez, T Paster, R Egan, W Kreutner, T Kung. 1997. Role of nitric oxide on eosinophilic lung inflammation in allergic mice. AM J Respir Cell Mol Biol 17, 436-442.

Flores J, JA Armijo, A Mediavilla. 1992. Farmacología humana. $2^{\text {a }}$ edición. Masson-Salvat Medicina.

Franchini M, U Gill, R Von Fellenberg, VV Bracher. 2000. Interleukin8 concentration and neutrophil chemotactic activity in bronchoalveolar lavage fluid of horses with chronic obstructive pulmonary disease following exposure to hay. Am J Vet Res 11, 1369-74

Fryer A, D Jacoby. 1998. Muscarinic receptors and control of airway smooth muscle. Am J Respir Crit Care Med 158, S154-S160.

Gerber H. 1973. Chronic Pulmonary Disease in the Horses. Equine Vet $J$ 5, 26-28.

Gerber H. 1989. The genetic basic of some equine diseases. Equine Vet J 21, 244-248.

Gerber V, NE Robinson, RJ Venta, J Rawson, AM Jefcoat, JA Hotchkiss. 2003. Mucin genes in horses airways: MUC5AC, but not MUC2, may play a role in recurrent airway obstruction. Equine Vet J 3, 252-7.

Gould HJ, BJ Sutton, AJ Beavil, RL Beavil, N McCloskey, HA Coker, D Fear, L Smurthwaite. 2003. The biology of IgE and the basis of allergy disease. Ann Rev Immunol 21, 579-628.

Griesenbach U, P Scheid, E Hillery, R DE Martin, L Huang, DM Geddes, EW Alton. 2000. Anti-inflammatory gene therapy directed at the airway epithelium. Gene Ther 4, 306-13.

Hare JE, L Viel, PM O'Byrne, PD Conlon. 1994. Effect of sodium cromoglycate on light racehorses with elevated metachromatic cell numbers on broncheoalveolar lavage and reduced exercise tolerance. J Vet Pharmacol Ther 17, 237-244.

Hare JE, L Viel. 1998. Pulmonary eosinophilia associated with increased airway responsiveness in young racing horses. J Vet Intern Med 12, 163-170.

Harmegnies NF, DH Duvivier, SN Vandenput, T Art, PM Lekeux, DM Votion. 2002. Exercise-induced pulmonary perfusion redistribution in heaves. Equine Vet J 34, 478-84.
Hockenjos P, Y Mumenoglu, H Gerber. 1981. Zur möglichen aetiologischen Bedeutung von Heumilben für allergisch bedingte Lungenkrankeiten des Pferdes. Schwiez Arch Tierheilk 123, 129-136.

Hoffmann AM. 1999. Broncheoalveolar lavage technique and cytologic diagnosis of small airway inflammatory disease. Equine Vet Educ 11, 330-336.

Holcombe SJ, C Jackson, V Gerber, A Jefcoat, C Berney, S Eberhardt, E Robinson. 2001. Stabling is associated with airway inflammation in young Arabian horses. Equine Vet J 33, 244-249.

Honjo T, K Kinoshita, M Muramatsu. 2002. Molecular Mechanism of Class Switch Recombination: linkage with Somatic Hypermutation. Ann Rev Immunol 20, 165-196

Jackson CA, C Berney, AM Jefcoat, NE Robinson. 2000. Environmen and prednisone interactions in the treatment of recurrent airway obstruction (heaves). Equine Vet J 32, 432-438.

Jackson KA, JL Stott, DW Horohov, JL Watson. 2004. IL-4 induced CD23 (FceRII) up-regulation in equine peripheral blood mononuclear cells and pulmonary alveolar macrophages. Vet Immun Immunopath 101, 243-250.

Kinoshita K, T Honjo. 2001. Linking class-switch recombination with somatic hypermutation. Nat Rev Mol Biol 2, 493-503.

Kurup V, J Xia, R Crameri, D Rickaby, H Chol, S Fluckiger, K Blaser, C Dawson, K Kelly. 2001. Purified recombinant A. fumigatus allergens induce different response in mice. Clinical Inmumunol 98, 327-336.

Lapointe JM, JP Lavoie, AA Vrins. 1993. Effects of triamcinolone acetonide on pulmonary function and broncheoalveolar lavage cytologic features in horses with chronic obstructive pulmonary disease. Am J Ves Res 54, 1310-1316.

Lavoie JP, K Maghni, M Desnoyers, R Taha, JG Martin, Q Hamid. 2000. Brocheoalveolar cells from horses with "heaves" express a Th2-type cytokine profile. Proceedings of the Annual Veterinary Medical forum 18, Pp 751.

Lavoie JP, K Maghni, M Desnoyers, R Taha, J Martin, Q Hamid. 2001. Neutrophilic airway inflammation in horses with heaves is characterized by a Th2-type cytokine profile. Am J Respir Crit Care Med 164, 1410-1413.

Lekeux P, D Duvivier. 2001. Aerosol Therapy. International Veterinary Information Service. Ithaca, New York, USA.

Levine SJ. 1995. Bronchial epithelial cell-cytokine interactions in airways ephitelium. J Invest Med 43, 241-249.

McGorum B, J Ellison, R Cullen. 1998. Total and respirable dust endotoxin concentrations in three equine management systems. Equine Vet J 30, 430-434.

McGorum B, PM Dixon. 1994. The analysis and interpretation of equine bronchoalveolar lavage fluid (BALF) cytology. Equine Vet Educ 4, 203-209.

Marsh DG, A Lockhart, ST Holgate. 1993. The genetics of asthma. Blackwell Scientific Publications, Oxford, England.

Marti E, H Gerber, G Essich, J Oulehla, S Lazary. 1991. The genetic basic of equine allergic diseases. Chronic hypersensitivity bronchitis. Equine Vet J 23, 457-460.

Marti E, L Harwood. 2002. Genetics of human asthma and equine recurrent airway obstruction: can these two disease e compared? Pferdheikunde 18, 587-593.

Mekori Y, D Metcalfe. 1999. Mast Cell-T interactions. J Allergy Clin Immunol 104, 517-523.

Moore BR, JH Cox. 1996. Diagnostic use of broncheoalveolar lavage in horses. Equine Practice 5, 7-15.

Newton J, J Wood. 2002. Evidence of an association between inflammatory airway disease and EIPH in young Thoroughbreds during training. Equine Vet J 34, 417-24.

Pujols L, J Mullol, A Torrego, C Picado. 2004. Glucocoticoid receptors in human airway. Allergy 59, 1042-1052.

Olszewski MA, XY Zhang, NE Robinson. 1999. Pre-and postjunctional effects of inflammatory mediators in horses airways. Am J Physiol 277, L327-L333. 
Robinson NE. 2001. International Workshop on Equine Chronic Airway Disease Michigan State University. Equine Vet J 33, 5-19.

Robinson NE. 2003. Current Therapy in Equine Medicine 4. Philadelpia. WB Saunders Co. USA.

Rush BR, AA Worster, MJ Flmino, CJ Matson, JE Hakala. 1998a. Alteration in adrenocortical function in horses with recurrent airway obstruction after aerosol and parenteral administration of beclomethasone dipropinate and dexamethasone, respectively. Am $J$ Vet Res 8, 1044-7.

Rush BR, ES Raub, WS Rhoad, MJ Flamino, CJ Matson, JE Hakala, JR Gillespie. 1998b. Pulmonary function in horses with recurrent airway obstruction after aerosol and parenteral administration of beclomethasone dipropinate and dexamethasone, respectively. Am J Vet Res 8, 1039-43.

Rush BR, MJ Flamino, CJ Matson, JE Hakala, W Shuman. 1998c. Cytologic evaluation of bronchoalveolar lavage fluid from horses with recurrent airway obstruction after aerosol and parenteral administration of beclomethasone dipropinate and dexamethasone, respectively. Am J Vet Res 8, 1033-8.

Rush BR, ES Raub, MM Thomsen, EG Davis, CJ Matson, JE Hakala. 2000. Pulmonary function and adrenal gland suppression with incremental doses of aerosolized beclomethasone dipropionate in horses with recurrent airway obstruction. Am. J. Vet. Res 3, 35964.

Saunders C, F Bureau, R Turlej, L Fievez, S Dogne, N Kirschvink, P Lekeux. 2001. Homodimer activity distal airway cells determines lung dysfuction in equine heaves. Vet Immunol Immonolpathol $80,315-26$

Saunders MA, JA Mitchell, PM Seldon, PJ Barnes, MA Giembyez, MG Belvisi. 1997. Release of granulocyte-macrophage colonystimulating factor by human cultured airway smooth muscle cells: Suppression by dexamethasone. Br J Pharmacol 120, 545-546.

Schapfer W. 1939. Untersusuchungen uber die Erblichkeit und das Wesen des Lungendampfes beim Pferd. Tierarztl Rundsch 45, 595-601.

Schleimer RP, CA Sterbinsky, CA Kaiser, DA Bickel, K Klunk, Ktomoika, W Newman, MA Luscinskas, MA Gimbrone,
BW McIntire, BS Buchner. 1992. Interlukin-4 induces adherence of human eosinophils and basophils but not neutrophils to endothelium: Association with expression of VCAM-1. J Immunol 148, 1086-1092.

Schultz J, J Arrang, M Garbarg, H Pollard, M Ruat. 1991. Histaminergic transmission in the mammalian brain. Physiol Rev $71,1-51$.

Steinke J, L Borish. 2001. Th2 cytokines and asthma Interleukin-4: its role in the pathogenesis of asthma, and targeting it for asthma treatment with interleukin-4 receptor antagonist. Resp Res 2, 6670.

Soma LR, J Beech, NH Gerber. 1987. Effects of cromolyn in horses with cronic obstructive pulmonary disease. Vet Res Commun 11, 339-351.

Thomson JR, EA McPherson. 1981. Prophylactic effects of sodium cromoglycate on chronic obstructive pulmonary disease in the horses. Equine Vet J 13, 243-246.

Umland S, R Schleimer, S Johnston. 2002. Review of the molecular and cellular mechanisms of action of glucocorticoids for use in asthma. Pulmon Pharmacol \& therapeutics 15, 35-50.

Vignola AM, AM Campbell, P Chanez, P Lacoste, F Michel, P Godard, J Bousquet. 1993. Activation of histamine by bronchial epithelial cells from nonasthmatic subjects. Am J Resp Crit Care Med 9, 411-417

Varner AE, WW Busse. 1996. Are you undertreating inflammation in asthma? J Resp Dis 17, 656-668.

Wagner B, G Siebenkotten, A Radbruch, W Leibold. 2001. Nucleotide sequence and restriction fragment length polymorphisms of the equine Ce gene. Vet Immun Immunopath 82, 193-202.

Wynn TA. 2003. IL-13 Effector Functions. Annи Rev Immnol 21, 425456.

Yamauchi K, Y Martinet, P Basset, GA Fells, RG Crystal. 1988. High levels of transforming growth factor- $B$ are present in the epitelial cell lining fluid of the normal human lower respiratory tract. $A m$ Rev Resp Dis 137, 1360-1363

Zhang XY, NE Robinson, FX Zhu. 1999. Modulation of Ach release from airway cholinergic nerves in horses with recurrent airway obstruction. Lung Cell Mol Physiol 20, L7769-L775. 